\title{
Influence of Surface-profile and Movement-path of Roller on Thickness Thinning during Multi-pass Deep Drawing Spinning
}

\author{
Qinxiang Xia ${ }^{1, a}$, Junhao Zhang ${ }^{1}$, Chenglong Huang ${ }^{1}$ and Xiuquan Cheng $^{2}$ \\ ${ }^{1}$ School of Mechanical and Automotive Engineering, South China University of Technology, China \\ ${ }^{2}$ Aircraft Maintenance Engineering College, Guangzhou Civil Aviation College, China
}

\begin{abstract}
Over thinning is a serious defect influencing the forming quality of spun workpiece during multi-pass deep drawing spinning. Surface-profile and movement-path of roller are the key factors influencing the thinning ratio of wall thickness of spun workpiece. The influence of surface-profile and movement-path of roller on thickness thinning were studied based on numerical simulation and experimental research, four groups of forming experiments were carried out under the combination of the different surface-profile of roller (R12 and R25-12) and movement-path of roller (spinning from the bottom of the blank and spinning from the middle of the blank). The results show that both the surface-profile and movement-path of roller have great influence on wall thickness thinning during multi-pass deep drawing spinning; and compared with the movement-path of roller, the influence of surface-profile of roller is more significant. The experimental results conform well to the simulation ones. It indicates that the FEA model established is reasonable and reliable.
\end{abstract}

\section{Introduction}

Deep drawing spinning is a kind of forming process that the diameter of the blank is reduced mainly by the radial drawing, which is the most widely used conventional spin-forming process ${ }^{[1-2]}$. Shielding case of high voltage switch is a kind of thin-walled rotational part with deep cavity, which is usually manufactured by welding after stamping. Compared with the welding after stamping, multi-pass deep drawing spinning has the advantages of low production cost and high material utilization ${ }^{[3]}$. However, due to the characteristics of deep cavity and thin wall of shielding case, over thinning defect occurs easily during multi-pass deep drawing spinning.

For solving the over thinning problem during deep drawing spinning, Wang and Long ${ }^{[4]}$ studied the influence of the roller paths on tool forces, part wall thickness and stress variations in conventional metal spinning numerically. The results show that using the concave roller path tends to cause higher reductions of wall thickness of the spun part and using the convex roller path helps to maintain the original wall thickness unchanged. A greater curvature of the concave path would result in more thinning in wall thickness of the spun part. Zeng et al. ${ }^{[5]}$ researched the influence of roller paths and processing parameters on multi-pass drawing spinning of 6061 and SPCC plates experimentally. The results show that the distribution of wall thickness of the spun part is the most uniform when spinning with the movement-path of convex and concave curves under the forward and backward alternately spinning method. Lin et al. ${ }^{[6]}$ researched the influence of the movement-path of roller on multi-process drawing spinning of Q235 and 1060 plates experimentally. The results show that spinning from the middle of the blank is beneficial the material flow in the subsequent passes. Ma et al. ${ }^{[7]}$ analyzed the influence of the feed rate, fillet radius and entry tangential angle of roller on the forming quality during conventional spinning numerically. The results show that the wall thickness thinning decreases with the increasing of the fillet radius of roller. In order to improve the limit drawing ratio of one-pass deep drawing spinning, Xia et al. ${ }^{[8]}$ designed a kind of roller with composite surface-profile, which was composed of two different fillet radius, and pointed out that the large fillet radius was used to press down the blank previously, which was beneficial the material flow, therefore, the deformation turned to be more easier under the large fillet radius. On the other hand, the small fillet radius was mainly used for the part forming.

Due to the limitations of the researches, it is not effective to solve the problem of over thinning of the thin-walled shielding case with deep cavity in practical applications. In this paper, the feasibility and influence of surface-profile and movement-path of roller on wall thickness thinning during multi-pass deep drawing spinning of thin-walled shielding case with deep cavity are studied.

\section{Feasibility analyses of surface-profile and movement-path of roller}

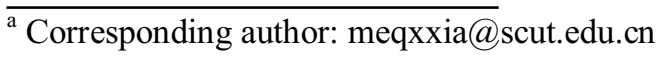




\subsection{Analysis of surface-profile of roller}

The fillet radius of roller has a great influence on the forming quality of parts during multi-pass deep drawing spinning ${ }^{[1]}$. The composite surface-profile roller composes of two different fillet radius, $R_{1}$ and $R_{2}$ (as shown in Fig.1), as reported by Xia et al. ${ }^{[8]}$. The main function of $R_{1}$ is to press down the blank previously and that of the $R_{2}$ is to form the blank. For the aluminum blank with diameter between $150 \sim 300 \mathrm{~mm}$, the range of the fillet radius $R_{2}$ is $12 \sim 15 \mathrm{~mm}^{[2]}$. Therefore, the value of $R_{2}$ was selected as $12 \mathrm{~mm}$, and the values of $R_{1}$ were selected as $25 \mathrm{~mm}, 30 \mathrm{~mm}$ and $45 \mathrm{~mm}$ respectively (as shown in Fig.2).

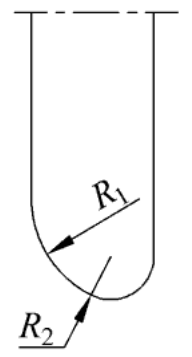

Figure 1. Composite surface-profile roller
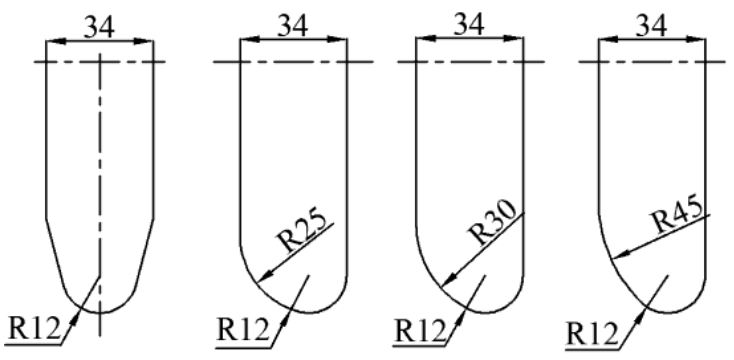

Figure 2. Rollers with different surface-profile

\subsection{Analysis of the movement-path of roller}

Fig. 3 shows the principle of traditional multi-pass deep drawing spinning process. It shows that in the initial stage of the forming process, the shape of blank is still closed to the plane (the diameter of blank is still large), which increases the forming resistance of the material on the blank edge. As a result, local forming and over thinning occur easily ${ }^{[9]}$.

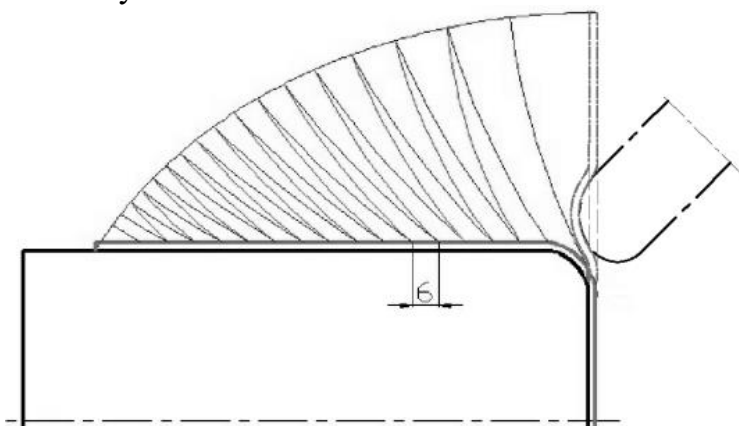

Figure 3. Principle of traditional multi-pass deep drawing spinning process

In order to reduce the negative influence of local forming, the initial spinning point $O_{1}$ starts from the middle of the blank was carried out during the multi-pass deep drawing spinning ${ }^{[6]}$ (as shown in Fig.4), hence to increase the drawing coefficient $m$ of the first pass (The drawing coefficient changes from $d_{0} / D_{0}$ to $d_{\mathrm{s}} / D_{0}$ ). In order to reduce the influence of local forming, according to the range of complete drawing ${ }^{[9]}, d_{s} / D_{0}$ was selected as 0.7 . In this case, the distance between the starting point $O_{1}$ of spinning and the edge of the blank $A$ is $30 \mathrm{~mm}$.

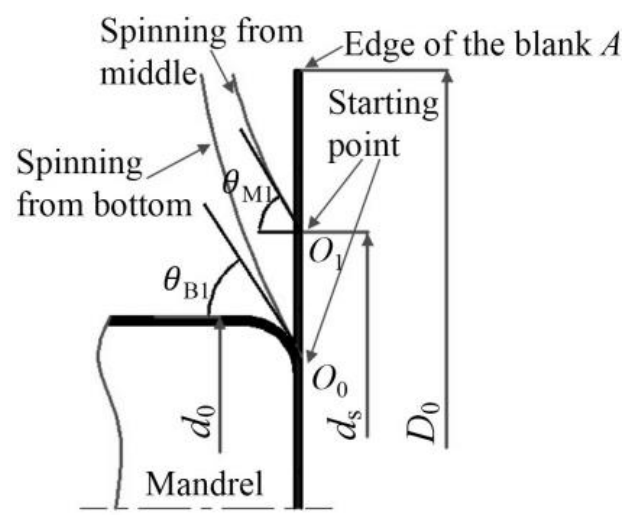

Figure 4. Diagram of movement-path of roller

The second pass of spinning starts from the bottom of the blank (as shown in Fig.5). The deformation of the second pass is smaller than that of the first pass spinning from the bottom of the blank, therefore, the negative influence of local forming is decreased.

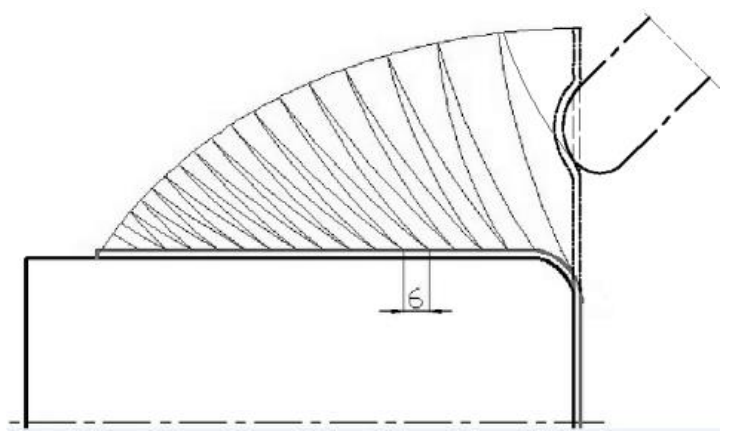

Figure 5. Path of spinning from middle of the blank

Furthermore, the elevation angle $\theta_{1}$ of first pass has great influence on the thinning ratio $\Psi_{i}$ of wall thickness $\left(\Psi_{i}=\left(t_{\mathrm{i}-1}-t_{\mathrm{i}}\right) / t_{\mathrm{i}-1}\right.$, where $t_{i-1}$ is the wall thickness of workpiece after $i-1$ passes spinning, $t_{i}$ is the wall thickness of workpiece after $i$ passes spinning) during multi-pass deep drawing spinning. The smaller the elevation angle $\theta_{1}$ of the first pass is, the smaller the thinning ratio $\Psi$ of wall thickness will be, under the condition of no wrinkling occurring ${ }^{[2]}$. The range of elevation angle $\theta_{1}$ of the first pass for aluminum alloy is usually from $50^{\circ}$ to $60^{\circ[2]}$. Wrinkling may occur if $\theta_{1}$ is less than $50^{\circ}$, while fracture may occur if $\theta_{1}$ is larger than $60^{\circ[2]}$. Therefore, for the simulation and experimental, the elevation angles $\theta_{\mathrm{M}}$ of the first and the second pass were selected as $\theta_{\mathrm{M} 1}=55^{\circ}, \theta_{\mathrm{M} 2}=60^{\circ}$ respectively during spinning from the middle of the blank; the elevation angle $\theta_{\mathrm{B} 1}$ of the first pass was selected as $\theta_{\mathrm{B} 1}=60^{\circ}$ during the simulation of the spinning from the bottom of the blank. 


\section{Finite element simulation results}

\subsection{Establishment of finite element model}

A three dimensional finite element model of multi-pass deep drawing spinning was established based on software-MSC.MARC (as shown in Fig.6), which compose of mandrel, roller, tail stock and blank. According to the deformation characteristics of the deep drawing spinning, the contact pairs are established between the mandrel, roller, tail stock and roller. In the FEA model, the blank is fixed between mandrel and tail stock, and its deformation is restricted by mandrel and tail stock. The part of blank which does not contact with the mandrel and tail stock is free, and plastic deformation occurs under the action of the roller. The mandrel, roller and tail stock are set as rigid body due to their negligible deformation during spinning and without discretization ${ }^{[10]}$. In the FEA model, the modified Coulomb friction model was adopted. The Coulomb friction coefficient $(\mu)$ between the roller and the blank is taken as $0.1^{[11]}$. The tail stock and the blank are tied together by using the glue function of the Marc i. e, a large separating force is defined to exist between the tail stock and blank, the action force between the tail stock and blank might not surpass it, so that the tail stock and blank glued firmly together. During the spinning, the deformation of the materials clamped between the mandrel and tail stock is too small and can be ignored, therefore this part is not discretized, which can reduce the number of grid and improve the computational efficiency. The blank is discretized into 22320 8-node structural 3-D solid shell elements with 45360 nodes. The parameters of blank (1060-O aluminum plate) used for the finite element model are shown in Table 1.

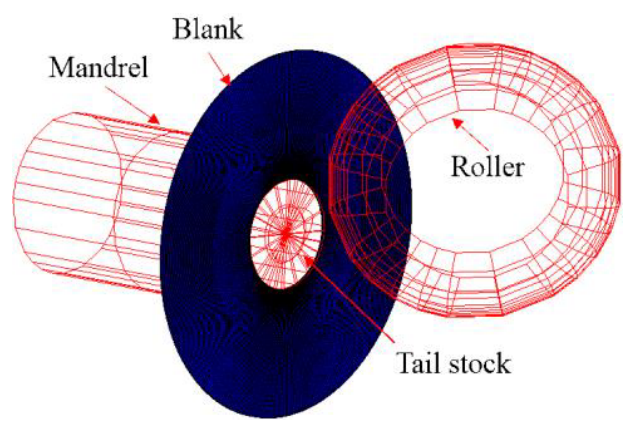

Figure 6. Finite element model of deep drawing spinning

Table 1. Parameters of the 1060-O aluminum blank

\begin{tabular}{|c|c|c|c|c|c|c|c|c|}
\hline $\begin{array}{c}\text { Diameter of } \\
\text { blank } \\
/ D_{0} / \mathrm{mm}\end{array}$ & $\begin{array}{c}\text { Thickness of } \\
\text { blank } \\
/ t / \mathrm{mm}\end{array}$ & $\begin{array}{c}\text { Yield } \\
\text { strength } \\
/ \sigma_{\mathrm{s}} / \mathrm{MPa} \\
\end{array}$ & $\begin{array}{c}\text { Tensile } \\
\text { strength } \\
/ \sigma_{\mathrm{b}} / \mathrm{MPa} \\
\end{array}$ & $\begin{array}{l}\text { Elongation } \\
\qquad / \delta / \%\end{array}$ & $\begin{array}{l}\text { Young's } \\
\text { modulus } \\
/ E / \mathrm{GPa} \\
\end{array}$ & $\begin{array}{c}\text { Poisson's } \\
\text { ratio } \\
/ \mu \\
\end{array}$ & $\begin{array}{c}\text { Hardening } \\
\text { exponent } \\
/ n\end{array}$ & $\begin{array}{c}\text { Enhancement } \\
\text { coefficient } \\
/ K \\
\end{array}$ \\
\hline 200 & 1.8 & 38 & 107 & 46 & 69 & 0.3 & 0.28 & 120.3 \\
\hline
\end{tabular}

\subsection{Analysis of simulation results}

\subsubsection{Influence of surface-profile of roller on thinning ratio of wall thickness of workpiece}

Table 2 shows the simulation results of wall thickness of workpiece after the first and second passes spinning under the different surface-profile of roller when spinning from the bottom of the blank (as shown in Fig.3), and the main processing parameters adopted in the simulation are as follows: the elevation angle $\theta_{\mathrm{B} 1}=60^{\circ}$, feed rate of roller $f=2.5 \mathrm{~mm} / \mathrm{r}$, the rotational speed of mandrel $n=500 \mathrm{rpm}$ and the diameter of roller $D_{\mathrm{R}}=160 \mathrm{~mm}$, the distance between every two passes $p=6 \mathrm{~mm}$.

As shown in Table 2, after the first pass spinning, the thinning ratio $\Psi$ of wall thickness is the smallest when using the roller with composite surface-profile of R30-12, and is the secondary smallest when using the roller with composite surface-profile of R25-12. This is because that the blank is closed to the plane shape during the first pass spinning, and all the contact positions between the blank and rollers locate in the range of $R_{1}$ (as shown in Fig.7), which is equivalent that the spin-forming occurs under the roller with single surface-profile $R_{1}$. The bigger the $R_{1}$ is, the smaller the wall thickness reduction would be. Therefore, the thinning ratio $\Psi$ of wall thickness under the roller with composite surface-profile of R30-12 is smaller than that of R25-12. With the increasing of $R_{1}$, the contact area between $R_{2}$ and blank increases, and between $R_{1}$ and blank decreases. The $R_{1}$ doesn't contact the blank anymore when $R_{1}$ is over large, and the spinforming hereby occurs only under the roller with the single surface-profile $R_{2}$, such as the roller R45-12. Therefore, the thinning ratio $\Psi$ under the roller R45-12 and R12 is almost the same.

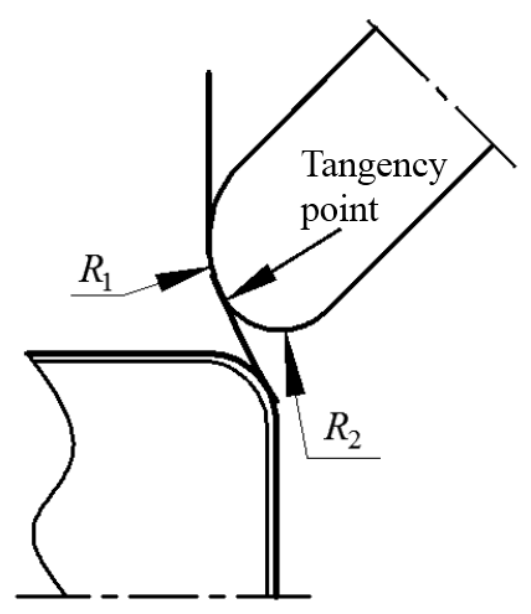

Figure 7. Contact situation between the roller and blank during the first pass spinning 
Table 2. Simulation results of wall thickness after the first and second passes spinning under different surface-profile of roller

\begin{tabular}{ccccc|cccc}
\hline & \multicolumn{4}{c|}{ The first pass } & \multicolumn{4}{c}{ The second pass } \\
\cline { 2 - 11 } & $\begin{array}{c}\text { Minimum } \\
\text { wall } \\
\text { thickness } \\
t_{\min } / \mathrm{mm}\end{array}$ & $\begin{array}{c}\text { Maximum } \\
\text { thinning } \\
\text { ratio } \\
\Psi_{\max } / \%\end{array}$ & $\begin{array}{c}\text { Wall } \\
\text { thickness } \\
\text { deviation } \\
\Delta t / \mathrm{mm}\end{array}$ & $\begin{array}{c}\text { Mean wall } \\
\text { thickness } \\
/ \mathrm{mm}\end{array}$ & $\begin{array}{c}\text { Minimum } \\
\text { wall } \\
\text { thickness } \\
t_{\min } / \mathrm{mm}\end{array}$ & $\begin{array}{c}\text { Maximum } \\
\text { thinning } \\
\text { ratio } \\
\Psi_{\max } / \%\end{array}$ & $\begin{array}{c}\text { Wall } \\
\text { thickness } \\
\text { deviation } \\
\Delta t / \mathrm{mm}\end{array}$ & $\begin{array}{c}\text { Mean wall } \\
\text { thickness } \\
/ \mathrm{mm}\end{array}$ \\
\hline $\mathrm{R} 12$ & 1.652 & 8.22 & 0.154 & 1.737 & 1.500 & 16.67 & 0.335 & 1.661 \\
$\mathrm{R} 25-12$ & 1.679 & 6.72 & 0.129 & 1.749 & 1.590 & 11.67 & 0.251 & 1.693 \\
$\mathrm{R} 30-12$ & 1.689 & 6.17 & 0.119 & 1.753 & 1.559 & 13.33 & 0.282 & 1.689 \\
$\mathrm{R} 45-12$ & 1.654 & 8.11 & 0.152 & 1.741 & 1.52 & 15.56 & 0.32 & 1.675 \\
\hline
\end{tabular}

Table 2 shows also that after the second pass spinning, the thinning ratio $\Psi$ of wall thickness of workpiece is the smallest when using the roller with composite surfaceprofile of R25-12. With the proceeding of passes, the thinning ratio $\Psi$ under roller R25-12 would be ultimately smaller than that of the roller R30-12. This is because that the contact area between $R_{2}$ and blank increases gradually with the blank pressing down (the blank is no longer a flat shape), and the $R_{1}$ and $R_{2}$ contact with the blank simultaneously (as shown in Fig.8). The main function of $R_{1}$ is to press down the blank previously during the first spinning pass, the contact area between the blank and roller during the following passes decreases with the decreasing of $R_{1}$, hence to decrease the flow resistance of the material, therefore, the thinning ratio $\Psi$ of wall thickness decreases. The maximum thinning ratio $\Psi_{\text {max }}$ under the roller with composite surface-profile of R25-12 after two-pass spinning is $11.67 \%$, which is reduced by $30 \%$ compared with spinning under the roller with the single surface-profile of R12 only.

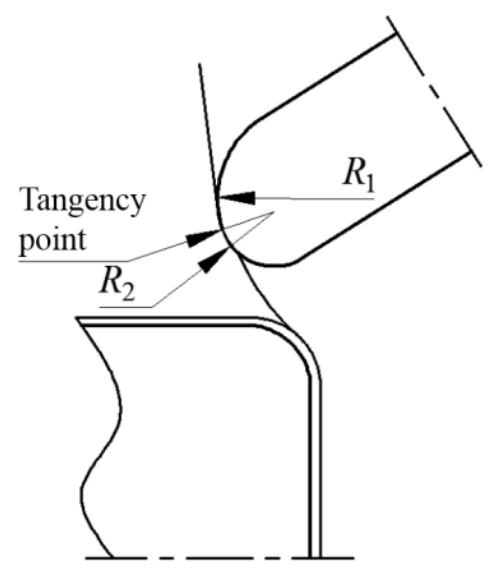

Figure 8. Contact situation between the roller and blank during the second pass spinning

\subsubsection{Influence of the movement-path of roller on the thinning ratio of wall thickness of workpiece}

Table 3 shows the simulation results of wall thickness of workpiece after the first and second passes spinning under the two different movement-path of roller shown in Fig.4. The constant processing parameters adopted in the simulation are as follows: the rotational speed of mandrel $n=500 \mathrm{rpm}$, the diameter of roller $D_{\mathrm{R}}=160 \mathrm{~mm}$, the fillet radius of rollers $r_{\rho}=12 \mathrm{~mm}$, the distance between every two passes $p=6 \mathrm{~mm}$; and the variable processing parameters adopted in the simulation are listed in Table 4.

Table 3. Simulation results of wall thickness

\begin{tabular}{ccccc}
\hline $\begin{array}{c}\text { Movement- } \\
\text { path of } \\
\text { roller }\end{array}$ & $\begin{array}{c}\text { Number } \\
\text { of the } \\
\text { pass }\end{array}$ & $\begin{array}{c}\text { Minimum } \\
\text { wall } \\
\text { thickness } \\
/ t_{\max } / \mathrm{mm}\end{array}$ & $\begin{array}{c}\text { Maximum } \\
\text { thickness } \\
\text { thinning } \\
\text { ratio } \\
/ \Psi_{\max } / \%\end{array}$ & $\begin{array}{c}\text { Deviation } \\
\text { of wall } \\
\text { thickness } \\
/ \Delta t / \mathrm{mm}\end{array}$ \\
\hline $\begin{array}{c}\text { Spinning } \\
\text { from middle }\end{array}$ & $\begin{array}{c}\text { First pass } \\
\text { Second } \\
\text { pass }\end{array}$ & 1.764 & 2 & 0.046 \\
$\begin{array}{c}\text { Spinning } \\
\text { from bottom }\end{array}$ & First pass & 1.736 & 3.56 & 0.076 \\
\hline
\end{tabular}

Table 4. Variable processing parameters used for simulation

\begin{tabular}{|c|c|c|c|}
\hline & \multirow{2}{*}{$\begin{array}{l}\text { Spinning } \\
\text { from } \\
\text { bottom }\end{array}$} & \multicolumn{2}{|c|}{ Spinning from middle } \\
\hline & & The first pass & $\begin{array}{c}\text { The second } \\
\text { pass }\end{array}$ \\
\hline $\begin{array}{c}\text { Elevation } \\
\text { angle } / \theta /^{\circ}\end{array}$ & 60 & 55 & 60 \\
\hline $\begin{array}{c}\text { Feed ration } \\
\mid f /(\mathrm{mm} / \mathrm{r})\end{array}$ & 2.5 & 3 & 2.5 \\
\hline
\end{tabular}

Table 3 shows that the thinning ratio $\Psi$ of wall thickness when spinning from the middle of blank in the first pass is very small. The maximum thinning ratio $\Psi_{\max }$ of the first pass is only $2 \%$, and is increased to $5.56 \%$ (the total maximum thinning ratio $\Psi$ of the first and two passes) after the second pass (the minimum of the wall thickness $t_{\min }$ is $1.736 \mathrm{~mm}$ ), while the maximum thinning ratio $\Psi_{\max }$ of first pass spinning from the bottom of blank was $8.11 \%$ (the minimum of the wall thickness $t_{\min }$ is $1.652 \mathrm{~mm}$ ). It indicates that the thinning ratio $\Psi$ of wall thickness can be decreased effectively by spinning from the middle of the blank.

\section{Experimental research}

\subsection{Experimental Conditions}

Fig.9 shows the diagram of the shielding case of the high voltage switch. The dimensions of the shielding case are as follows: the inner diameter $d=88 \mathrm{~mm}$, the height $H=96.8 \mathrm{~mm}$, the inner fillet radius $r=10 \mathrm{~mm}$, the wall thickness $t=1.8 \mathrm{~mm}$. 
The experimental was carried out on a two-wheel numerical controlled spinning machine and the processing parameters used in the experimental are the same as that of the simulation.

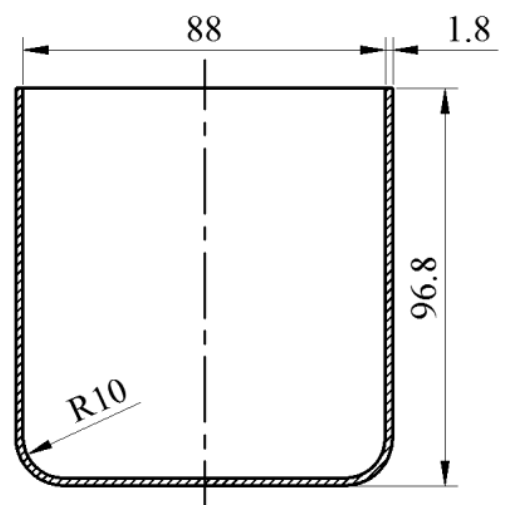

Figure 9. Diagram of shielding case of high voltage switch

\subsection{Comparison of experimental and simulation results}

Fig.10 shows the comparison of wall thickness between the experimental and simulation results. It shows that the distributions of wall thickness between the experimental and the simulation results conform well to each other, the maximum error is only $0.02 \mathrm{~mm}$ (the relative error is $1.1 \%)$. It indicates that the finite element model established is reasonable and reliable.

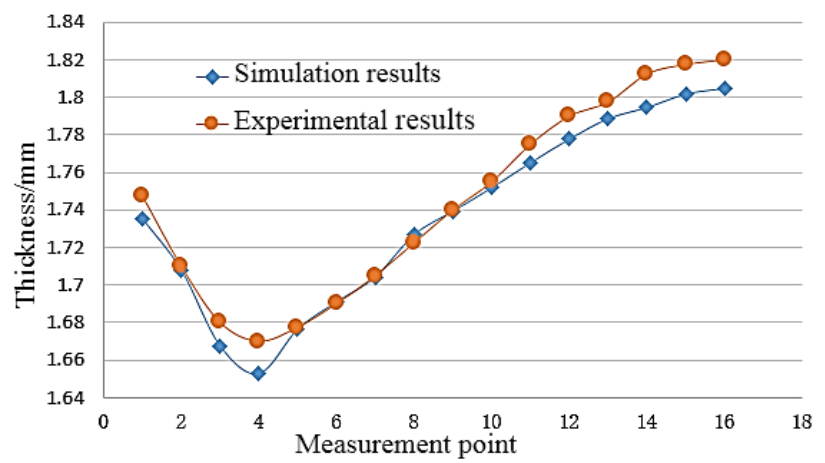

a) Distribution of wall thickness after the first pass when spinning from the bottom of the blank

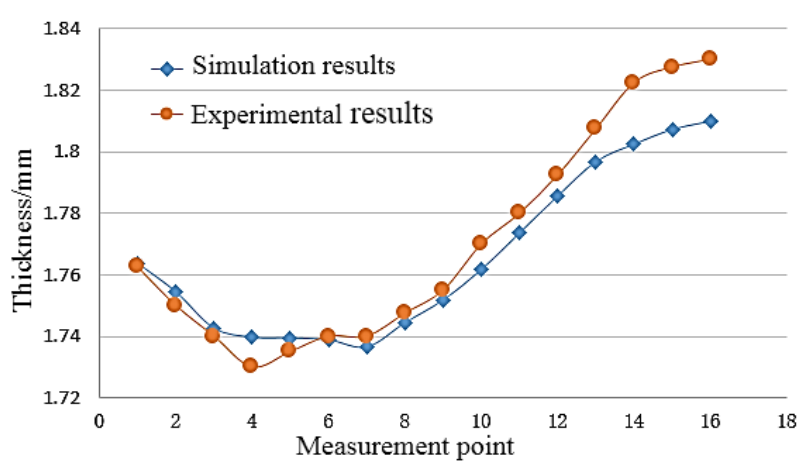

b) Distribution of wall thickness after the second pass when spinning from the middle of the blank

Figure 10. Comparison of the distribution of wall thickness of workpiece between experimental and simulation results

\subsection{Trial production of shielding case of the high voltage switch}

Four groups of forming experiments were carried out under the combination of the different surface-profile of roller (R12 and R25-12) and movement-path of roller (spinning from the bottom of the blank and spinning from the middle of the blank), as listed in Table 5. The total number of the passes is 31 when spinning from the bottom of the blank, while that of the number is 32 passes when spinning from the middle of the blank.

Table 5. Experimental scheme

\begin{tabular}{ccc}
\hline No. & $\begin{array}{c}\text { Surface-profile of } \\
\text { roller }\end{array}$ & Movement-path of roller \\
\hline 1 & R12 & Spinning from bottom \\
2 & R12 & Spinning from middle \\
3 & R25-12 & Spinning from bottom \\
4 & R25-12 & Spinning from middle \\
\hline
\end{tabular}

Fig.11 shows the distribution of the wall thickness of spun workpiece under four combinations of the different surface-profile and movement-path of roller, and Table 6 shows the totally maximum thickness thinning ratio $\Psi_{\max }$ and the relative maximum thickness thinning ratio $\Delta \Psi_{i}$ $\left(\Delta \Psi_{i}=\Psi_{\max i} / \min \left(\Psi_{\max i}\right)\right.$, where $\Psi_{\max i}$ is the maximum thickness thinning ratio of the experiment $i$ ). As shown in Fig.11 and Table 6, both of the surface-profile and movement-path of roller have great influence on wall thickness thinning during multi-pass deep drawing spinning; and compared with the movement-path of roller, the influence of surface-profile of roller is more significant.

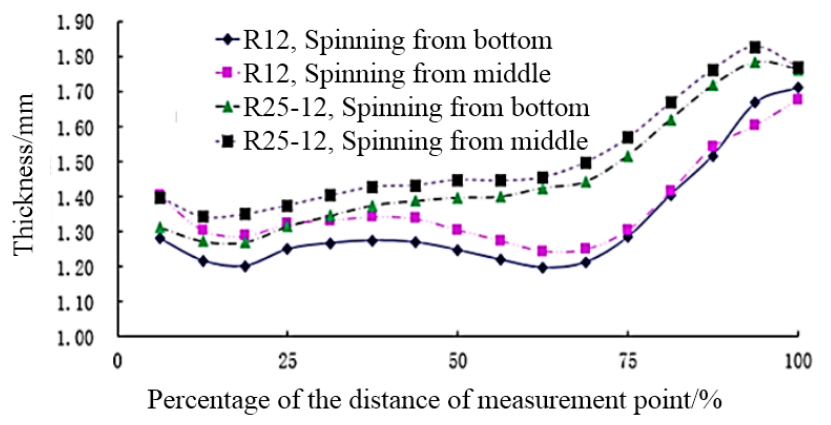

Figure 11. Distribution of wall thickness of workpiece of experimental results

Table 6. Thinning ratio $\Psi$ of wall thickness of the four groups of experiments

\begin{tabular}{ccccc}
\hline No. & 1 & 2 & 3 & 4 \\
\hline $\begin{array}{c}\text { Total maximum thickness } \\
\text { thinning ratio } / \Psi_{\max } / \%\end{array}$ & 33.3 & 30.6 & 29.4 & 25.6 \\
$\begin{array}{c}\text { Relative maximum thickness } \\
\text { thinning ratio } / \Delta \Psi_{i}\end{array}$ & 1.30 & 1.20 & 1.15 & 1 \\
\hline
\end{tabular}


Fig.12 shows the workpiece obtained by the multi deep-drawing spinning under the four combinations of the different surface-profile and movement-path of roller listed in Table 5. As shown in Fig.12, the height of the spun workpiece obtained by roller R12 and spinning from the bottom of the blank is obviously higher than that of the three other combinations. It indicates the wall thickness thinning under the R12 and spinning from the bottom of the blank is the most serious.

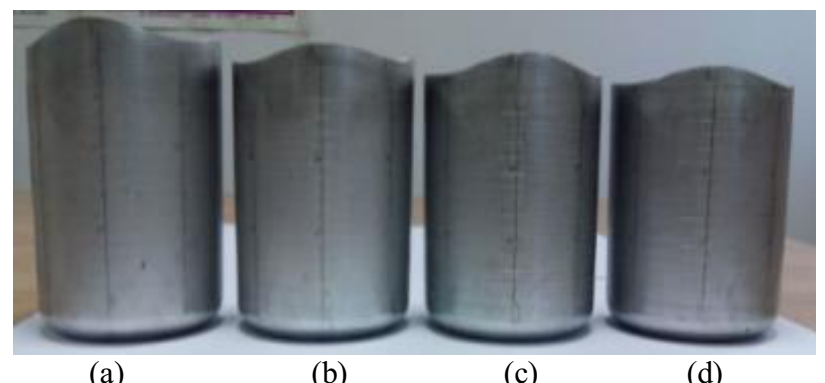

(a)

(b)

(c)

(d)

Figure 12. Spun workpiece: (a) R12, Spinning from bottom (b) R12, Spinning from middle (c) R25-12, Spinning from bottom (d) R25-12, Spinning from middle

The experimental results show that the thinning ratio $\Psi$ of wall thickness can be effectively reduced by spinning with composite surface-profile roller and spinning from the middle of the blank, but the influence decreases with the increasing of the spinning pass (as shown in Fig.11 and Table 2). The total thinning ratio $\Psi$ of wall thickness increases rapidly with the increasing of the spinning pass, which leads to the decline of the influence of surface-profile and movement-path of roller on the thinning ratio $\Psi$ of wall thickness of workpiece. Therefore, the number of the spinning pass should be controlled strictly to avoid the over thinning defect.

\section{Conclusions}

The influence of surface-profile and movement-path of roller on thinning ratio $\Psi$ of wall thickness of workpiece during multi-pass deep drawing spinning is researched, the conclusions are as follows:

(1) The surface-profile and movement-path of roller have great influence on wall thickness thinning during multi-pass deep drawing spinning, and compared with the movement-path of roller, the influence of surface-profile of roller is more significant.

(2) For the 1060-O pure aluminum, the thinning ratio $\Psi$ of wall thickness is the smallest when spinning with the composite surface-profile roller of R25-12 and spinning from the middle of the blank.

(3) The influence of the surface-profile and movement-path of roller on the thinning ratio of wall thickness decreases with the increasing of the spinning pass, the number of the spinning pass should be controlled strictly to avoid the over thinning defect.

\section{Acknowledgments}

This project was financially supported by National Natural Science Foundation of China (51075153) and Open Foundation of National Engineering Research Centre of Near-net shape Forming for Metallic Materials, South China University of Technology(2012001).

\section{References}

1. Q.X. Xia, G.F. Xiao, H. Long, X.Q. Cheng, X.F. Sheng. Int J Mach Tools Manuf, 85(2014): 100121.

2. O. Music, J.M. Allwood, K. Kawai, A review of the mechanics of metal spinning, J Mater Process Technol, 210 (1) (2009) : 3-23.

3. C.C. Wong, T.A. Dean, J. Lin. Int. J. Mach Tools Manuf, 43(2003): 1419-1435.

4. L. Wang, H. Long, J. Mater. Process. Technol., 211(2011): 2140-2151.

5. C. Zeng, S.J. Zhang, Q.X. Xia, H.X. Xie. Forging \& Stamping technology, 2014, 39(1): 58-63 (In Chinese).

6. B. Lin, S.R. Zhou, J.J. Liu, J.M. Gu, D.H. Wang, W. Cai. Forging \& Stamping technology, 2010, 35(4): 56-61 (In Chinese).

7. F. Ma, H.Yang, M. Zhan. Mechanical Science and Technology for Aerospace Engineering, 2007, 26(3): 309-313 (In Chinese).

8. Q.X. Xia, S. Shima, H. Kotera, D. Yasuhuku. J. Mater. Process. Technol., 159 (2005): 397-400.

9. X.P. Wang. Stamping handbook. Beijing: China Machine Press, 2004 (In Chinese).

10. K. Essa, P. Hartley. Int. J. Mater. Form., 2(2009): 271-281.

11. Q.X. Xia, X.Q. Cheng, H. Long, F. Ruan. Int J Adv Manuf Technol, 59(1-4) : 263 272. 